\title{
A Highly Sensitive Luminescent Biosensor for the Microvolumetric Detection of the Pseudomonas aeruginosa Siderophore Pyochelin
}

\author{
Daniela Visaggio, ${ }^{*}+$ Mattia Pirolo, Emanuela Frangipani, Massimiliano Lucidi, Raffaella Sorrentino, \\ Emma Mitidieri, Francesca Ungaro, Andrea Luraghi, Francesco Peri, and Paolo Visca*
}

Cite This: ACS Sens. 2021, 6, 3273-3283

Read Online

ACCESS 1

山ll Metrics \& More

回国 Article Recommendations

(s) Supporting Information

ABSTRACT: The pyochelin (PCH) siderophore produced by the pathogenic bacterium Pseudomonas aeruginosa is an important virulence factor, acting as a growth promoter during infection. While strong evidence exists for $\mathrm{PCH}$ production in vivo, $\mathrm{PCH}$ quantification in biological samples is problematic due to analytical complexity, requiring extraction from large volumes and timeconsuming purification steps. Here, the construction of a bioluminescent whole cell-based biosensor, which allows rapid, sensitive, and single-step PCH quantification in biological samples, is reported. The biosensor was engineered by fusing the promoter of the PCH biosynthetic gene $p c h E$ to the $l u x C D A B E$ operon, and the resulting construct was inserted into the chromosome of the

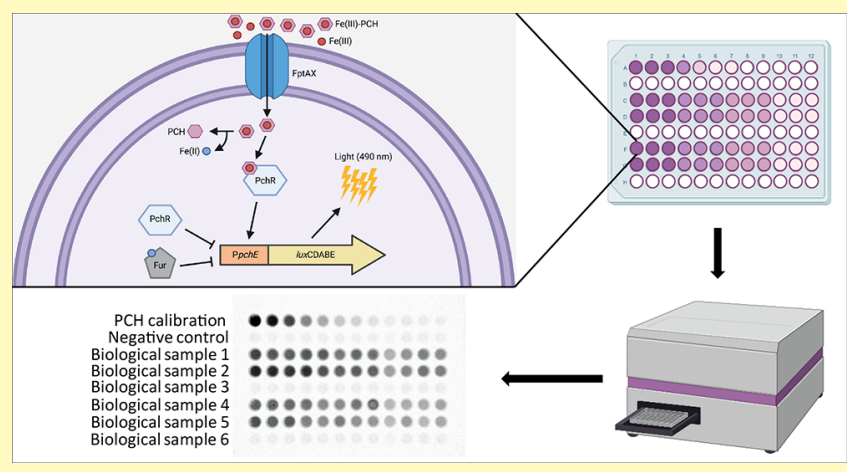
$\Delta p v d A \Delta p c h D \Delta f v A$ siderophore-null $P$. aeruginosa mutant. A bioassay was setup in a 96-well microplate format, enabling the contemporary screening of several samples in a few hours. A linear response was observed for up to $40 \mathrm{nM} \mathrm{PCH}$, with a lower detection limit of $1.64 \pm 0.26 \mathrm{nM}$ PCH. Different parameters were considered to calibrate the biosensor, and a detailed step-by-step operation protocol, including troubleshooting specific problems that can arise during sample preparation, was established to achieve rapid, sensitive, and specific PCH quantification in both $P$. aeruginosa culture supernatants and biological samples. The biosensor was implemented as a screening tool to detect PCHproducing $P$. aeruginosa strains on a solid medium.

KEYWORDS: bioluminescence, biosensor, luciferase, pyochelin, Pseudomonas aeruginosa, siderophore

Tisas issues and biological fluids of mammals are protected from invading pathogens by iron-binding proteins, which represent major components of the innate immunity. ${ }^{1}$ Therefore, during infection, bacteria are faced with a tremendous iron-starvation stress, which is inductive of siderophore (iron chelator) synthesis. ${ }^{2-4}$ The Gram-negative bacterium Pseudomonas aeruginosa is one of the most dreaded opportunistic pathogens in the hospital setting and represents the first cause of morbidity and mortality in cystic fibrosis (CF) patients. ${ }^{5} P$. aeruginosa produces two siderophores, namely, pyoverdine (PVD) and pyochelin $(\mathrm{PCH})$, which are endowed with very different structural and functional properties and capable of chelating Fe(III) with different affinities. 6,7

PVD is a dihydroxyquinoline-containing green fluorescent peptide showing very high affinity for $\mathrm{Fe}$ (III) ( $\mathrm{Kf}=10^{32}$ $\left.\mathrm{M}^{-1}\right) .{ }^{8,9}$ The role of PVD in P. aeruginosa pathogenicity has extensively been studied, since PVD is produced in large amounts and can easily be quantified both in vitro and in vivo, thanks to its strong fluorescence emission. ${ }^{10,11}$

$\mathrm{PCH}$ is the second siderophore produced by $P$. aeruginos $a^{12}$ and originates from the enzymatic condensation of salicylic acid with two cysteine molecules. ${ }^{13,14}$ The $\mathrm{PCH}$ structure contains three asymmetric carbons (C-4', C-2", C-4" $4^{\prime \prime}$ and exists as a mixture of the two interconvertible diastereomers PCH I $\left(4^{\prime} \mathrm{R}, 2^{\prime \prime} \mathrm{R}, 4^{\prime \prime} \mathrm{R}\right)$ and PCH II $\left(4^{\prime} \mathrm{R}, 2^{\prime \prime} \mathrm{S}, 4^{\prime \prime} \mathrm{R}\right){ }^{15}$ Its affinity for $\mathrm{Fe}$ (III) is $10^{28} \mathrm{M}^{-2}$. $^{16}$

The $\mathrm{PCH}$ biosynthetic genes are organized in two operons, pchDCBA and pchEFGHI. ${ }^{17} \mathrm{~A}$ third operon, $f p t A B C X$, encodes the FptA outer membrane receptor and the $\mathrm{FptX}$ inner membrane permease, which mediate active transport of $\mathrm{PCH}$ inside the $P$. aeruginosa cell. ${ }^{18}$ In the cytoplasm, the PCH$\mathrm{Fe}$ (III) complex binds the PchR regulator, which induces the expression of the $\mathrm{PCH}$ biosynthesis and uptake operons. ${ }^{19}$ PchR is a protein belonging to the AraC/XylS family of transcriptional regulators, which act as repressors or activators of gene expression depending on the absence or presence of a specific effector molecule, respectively. In particular, genes

Received: May 17, 2021

Accepted: August 11, 2021

Published: September 3, 2021 
implicated in PCH biosynthesis and uptake are repressed by PchR in the absence of cytoplasmic $\mathrm{PCH}$, while they are induced when PchR is activated upon PCH-(FeIII) binding. ${ }^{20,21}$ Since an excess of cytoplasmic iron is toxic for bacterial cells, all $P$. aeruginosa iron acquisition systems are repressed under iron-replete conditions by the binding of the ferric uptake regulator protein (Fur) to the promoter regions of PVD and PCH biosynthesis and uptake genes. ${ }^{14,22}$ This highly specific regulatory circuitry ensures $\mathrm{PCH}$ production when (i) cells are iron starved (hence, Fur repression is relieved) and (ii) $\mathrm{PCH}$ is effective in feeding the cell with iron (hence, PchR binds cytoplasmic PCH-Fe(III), activates PCH biosynthesis, and transport genes).

$\mathrm{PCH}$ has a major impact on $P$. aeruginosa pathogenesis, as it contributes to overcoming the iron starvation response of the host during bacterial infection. ${ }^{23} \mathrm{PCH}$ is crucial for feeding $P$. aeruginosa cells with iron and contributes to pathogenicity in a mouse model of lung infection. ${ }^{24}$ Indirect evidence of in vivo expression of $\mathrm{PCH}$ biosynthesis genes was inferred from transcriptional profiling of $P$. aeruginosa during septicemia, urinary tract, lung, and wound infections, ${ }^{25-28}$ and the $\mathrm{PCH}$ transport gene fptA was identified among the most highly expressed virulence genes in vivo. ${ }^{29}$ However, in vivo detection of $\mathrm{PCH}$ is problematic, and $\mathrm{PCH}$ production during $P$. aeruginosa infection was occasionally documented in $\mathrm{CF}$ sputum samples, which showed significant induction of pch genes. ${ }^{11,26}$ In vitro studies suggest that $\mathrm{PCH}$ is also responsible for secondary pathogenic effects on host tissues through the generation of hydroxyl radicals in combination with pyocyanin, which is an extracellular phenazine compound produced by $P$. aeruginosa. ${ }^{30,31}$

The paucity of information about $\mathrm{PCH}$ production levels during $P$. aeruginosa infection is due to the complexity of available methods to quantify this siderophore in biological samples. At present, $\mathrm{PCH}$ quantification methods rely on solvent extraction followed by concentration of the extract and $\mathrm{PCH}$ purification and detection by thin-layer chromatography, spectrofluorimetry, or HPLC. ${ }^{14,32-34}$ These methods are timeconsuming, require handling of hazardous solvents and specialized equipment for $\mathrm{PCH}$ extraction and quantification, respectively, and unavoidably cause non-negligible loss of material, which could ultimately result in the underestimation of the $\mathrm{PCH}$ concentration.

In this study, we report the construction of a bioluminescent whole cell-based biosensor for the rapid, specific, and singlestep quantification of $\mathrm{PCH}$, overcoming the numerous drawbacks of current $\mathrm{PCH}$ detection methods. The sensitivity, range of linear response, and specificity of the biosensor were experimentally determined. The biosensor was developed in the 96-well microtiter plate format and successfully used for $\mathrm{PCH}$ quantification in $P$. aeruginosa culture supernatants and biological samples, then adapted to the agar plate format for the qualitative screening of $\mathrm{PCH}$-producing $P$. aeruginosa clinical isolates.

\section{EXPERIMENTAL SECTION}

Bacterial Strains and Growth Media. Bacterial strains and plasmids used in this study are listed in Table S1. Escherichia coli and $P$. aeruginosa were grown in Luria-Bertani broth $(\mathrm{LB})^{35}$ and LB agar plates. The $P$. aeruginosa biosensor strain $\Delta p v d A \Delta p c h D \Delta f p v A$ PpchE::lux is freely available to the scientific community and can be provided upon request to the corresponding authors. When required, antibiotics were used at the following concentrations: ampicillin (Ap,
$100 \mu \mathrm{g} / \mathrm{mL})$, tetracycline $(\mathrm{Tc}, 12.5 \mu \mathrm{g} / \mathrm{mL})$, and gentamicin ( $\mathrm{Gm}, 10$ $\mu \mathrm{g} / \mathrm{mL})$ for E. coli; $\mathrm{Gm}(200 \mu \mathrm{g} / \mathrm{mL})$, carbenicillin $(\mathrm{Cb}, 250 \mu \mathrm{g} / \mathrm{mL})$, and $\mathrm{Tc}(100 \mu \mathrm{g} / \mathrm{mL})$ for $P$. aeruginosa. P. aeruginosa strains were also grown in the iron-poor casamino acid (DCAA) medium ${ }^{36}$ and in casamino acid (CAA) agarose plates (10 g/L CAA, Difco; $15 \mathrm{~g} / \mathrm{L}$ Certified Molecular Biology Agarose, Bio-Rad).

PVD Extraction and Quantification. PVD produced by $P$. aeruginosa strains was quantified after $24 \mathrm{~h}$ growth at $37^{\circ} \mathrm{C}$ in DCAA by measuring the absorbance at $405 \mathrm{~nm}$ of culture supernatants appropriately diluted in $0.1 \mathrm{M}$ Tris $-\mathrm{HCl}, \mathrm{pH}$ 8.0. Values were normalized to the cell density of the bacterial culture $\left(\mathrm{OD}_{600}\right)$, as previously described. ${ }^{37}$ PVD was purified as previously described. ${ }^{38}$ Briefly, $P$. aeruginosa $\Delta p c h D$ was grown in DCAA for $24 \mathrm{~h}$. The culture supernatant was purified by filtration through a Sep-Pak C18 Vac-Cartridge $3 \mathrm{cc}$ (Waters). The filtered culture supernatant containing PVD was loaded and washed with double-distilled water to remove unwanted components. PVD was then eluted with $50 \%$ (vol/vol) methanol, evaporated to dryness in a desiccator, and dissolved in a small volume of double distilled water. The PVD concentration was determined by spectrophotometric measurement of the apo form at $\mathrm{OD}_{405}\left(\varepsilon=1.4 \times 10^{4} \mathrm{M}^{-1} \mathrm{~cm}^{-1}\right)$.

PCH Extraction and Quantification. PCH was extracted from $P$. aeruginosa $\Delta p v d A$ by the ethyl acetate extraction of acidified $36 \mathrm{~h}$-old culture supernatants in DCAA. Briefly, the supernatant was adjusted to $\mathrm{pH} 1.5-2.0$ with $1 \mathrm{~N} \mathrm{HCl}$ and extracted with 1 volume of ethyl acetate. ${ }^{39}$ After evaporation of the organic phase, the dry residue was suspended in $100 \mu \mathrm{L}$ of methanol. PCH extracts were purified by an automatized reverse-phase chromatographer equipped with a UV-vis detector (BIOTAGE Isolera One Flash Chromatography System, RPC18 column, gradient water/methanol). The amount of apo- $\mathrm{PCH}$ was determined by spectrophotometric measurement at $\mathrm{OD}_{330}(\varepsilon=$ $\left.4400 \mathrm{M}^{-1} \mathrm{~cm}^{-1}\right) .{ }^{40}$ A $40 \mathrm{mM}$ of stock solution of $\mathrm{PCH}$ was prepared in dimethyl sulfoxide (DMSO) and stored at $-20{ }^{\circ} \mathrm{C}$ until used. The ethyl acetate extract of PAO1, $\Delta p v d A, \Delta p c h D$, and P. aeruginosa TR1 was also applied to a silica gel G (60F254) thin-layer chromatography (TLC) plate (Merck) using acetone:methanol:0.2 M acetic acid $(5: 2: 1)$ as the mobile phase. ${ }^{41} \mathrm{PCH}$ from TLC plates was qualitatively characterized by (i) yellow-green fluorescence emission under UV light ${ }^{42}$ and (ii) iron-binding capacity when sprayed with $0.1 \mathrm{M} \mathrm{FeCl}_{3}$ in $0.1 \mathrm{M} \mathrm{HCl}$ resulting in red-brown spots. ${ }^{42}$

Chemical Synthesis of $\mathrm{PCH}$ and Enantio-PCH. The two enantiomers $N$-methyl-L-cysteine and $N$-methyl-D-cysteine, which are required in the final step of $\mathrm{PCH}$ and enantio- $\mathrm{PCH}$ chemical synthesis, were prepared according to literature procedures, ${ }^{43,44}$ starting from commercially available $\mathrm{L}$ - or D-cysteine. In this synthetic procedure (Figure $S 1$ ), cysteine enantiomers were separately reacted with trityl alcohol in TFA to protect the thiol group as $S$-trytil, and then the amine group was protected as tert-butoxycarbonyl (Boc) carbamate that, after $N$-methylation with methyl iodide, gave the fully protected $S$-trityl, $N$-Boc, $N$-methyl L- or D-cysteine. The simultaneous deprotection of amino and thiol groups (Boc and trityl cleavage, respectively) gave the final $N$-methyl-L- or D-cysteine. $\mathrm{PCH}$ and enantio- $\mathrm{PCH}$ were then synthetized using the literature protocol ${ }^{45}$ over four steps (Figure S2). Commercially available 2-hydroxybenzonitrile was condensed with L-cysteine providing the thiazolidine intermediate. The treatment of the thiazolidine intermediate with $\mathrm{N}$ methyl-O-methyl hydroxylamine in the presence of condensing agents afforded the corresponding Weinreb amide, and the subsequent reduction with lithium aluminum hydride (LAH) gave aldehyde as a racemic mixture. The final condensation of aldehyde with the previously synthetized $N$-methyl-L-cysteine or its enantiomer $N$ methyl-L-cysteine followed by spontaneous cyclization gave PCH and enantio- $\mathrm{PCH}$, respectively, as a mixture of four diastereomers (Figure S2).

Generation of Plasmids and Reporter Strains. Unmarked inframe deletion mutants in $f p v A$ and $p c h R$ genes were constructed by suicide plasmid insertion mutagenesis. E. coli was used for recombinant DNA manipulations. The constructs for mutagenesis were generated by directional cloning into the pDM4 or pME3087

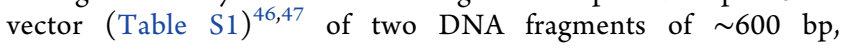


encompassing the regions upstream and downstream of the sequence to be deleted. Fragments were amplified by PCR, digested with the appropriate restriction enzymes, and cloned into pDM4 or pME3087, generating the derivative vectors $\mathrm{pDM} 4 \Delta f p v A$ and $\mathrm{pME} 3087 \Delta p c h R$ (Table S1). PCR primers and restriction enzymes used for cloning of PCR products are listed in Table S2. All constructs were verified by DNA sequencing. Deletion vectors were conjugally transferred from

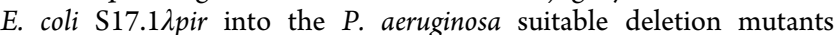
(Table S1). The in-frame deletion mutations were obtained by recombination, as previously described. ${ }^{46,47}$ All the deletion events were verified by PCR using primers flanking the deleted region and amplicon sequencing. For the generation of mini-CTX PpchE::lux insertion, a DNA fragment encompassing the $p c h E$ promoter was amplified using the primers listed in Table S2 from the $P$. aeruginosa PAO1 chromosome. The amplicon was digested with BamHI-HindIII and ligated in the mini-CTX-lux plasmid. The resulting mini-CTX PpchE::lux was transferred from E. coli S17.1 $\lambda$ pir into P. aeruginosa strains by conjugation. Excision of the mini-CTX plasmid was achieved by Flp-mediated recombination via pFLP2, as previously described. ${ }^{48}$

Biosensor Response to $\mathrm{PCH}$ and Other Iron-Binding Compounds. To test the biosensor response to $\mathrm{PCH}, \mathrm{P}$. aeruginosa PAO1 $\Delta p v d A \Delta p c h D \Delta f p v A$ PpchE::lux was grown for $16 \mathrm{~h}$ at $37^{\circ} \mathrm{C}$ in DCAA supplemented with $1 \mu \mathrm{M} \mathrm{FeCl}$. To exclude any iron carryover, the cells were washed with saline prior to being suspended in DCAA. The biosensor strain PAO1 $\Delta p v d A \Delta p c h D \Delta f p v A$ PpchE::lux was inoculated at final $\mathrm{OD}_{600}$ of $1,0.5$, and 0.25 into black, clear-bottom 96-wells microtiter plates (Greiner) in the presence of an increasing concentration of purified $\mathrm{PCH}$. Different inoculum volumes $(200,100$, and $50 \mu \mathrm{L})$ were tested in the assay. $\mathrm{OD}_{600}$ and light count per second (LCPS) were monitored every 15 min in a Tecan Spark $10 \mathrm{M}$ multilabel plate reader (Tecan, Männedorf, Switzerland) for up to $6 \mathrm{~h}$ at $25^{\circ} \mathrm{C}$. Once the optimal biosensor assay condition is defined $\left(\mathrm{OD}_{600}=0.25\right.$; final volume 50 $\mu \mathrm{L}$ per well), these parameters were applied in all subsequent assays. The limit of detection (LOD) and the limit of quantification (LOQ) of the $\mathrm{PCH}$ biosensor were determined according to the equations: $\mathrm{LOD}=3 \times(\mathrm{SD} / S)$ and $\mathrm{LOQ}=10 \times(\mathrm{SD} / S),{ }^{4,50}$ where $\mathrm{SD}$ is the standard deviation of the blank value ( $n=10$ replicates) and $S$ is the slope of the calibration curve (i.e., the sensitivity). The biosensor response was also assessed in the presence of chemically synthesized $\mathrm{PCH}$ and enantio-PCH, purified PVD, sodium salicylate (Sigma), deferoxamine (Desferal; Novartis), deferiprone (3-hydroxy-1,2dimethylpyridin-4(1H)-one; Sigma-Aldrich), and $\mathrm{FeCl}_{3}$ (Sigma) at the indicated concentrations.

Biological Fluids and CF Sputa. Sputum and first-morning urine specimens were collected from 10 healthy donors who tested culturenegative for $P$. aeruginosa. Each fluid was pooled, centrifuged $\left(13,000 \mathrm{~g}, 10 \mathrm{~min}, 4{ }^{\circ} \mathrm{C}\right)$, and sterilized through a $0.20 \mu \mathrm{m}$ filter. Sterile artificial tears (Irilens $0.4 \%$ ) were purchased from Montefarmaco (Italy). In addition, sputa from eight anonymous CF patients were provided by the clinical microbiology laboratory of Policlinico Umberto I, Rome (Italy), and processed as described above. Biological samples were stored at $-20^{\circ} \mathrm{C}$ until the assay.

PCH Quantification in $P$. aeruginosa Culture Supernatants and Biological Fluids. $\mathrm{PCH}$ detection in culture supernatants of $P$. aeruginosa strains and biological fluids (including CF sputa) was performed using the $P$. aeruginosa $\Delta p v d A \Delta p c h D \Delta f p v A$ PpchE::lux biosensor. $P$. aeruginosa strains (listed in Table S1) were grown for 24 $\mathrm{h}$ at $37^{\circ} \mathrm{C}$ in DCAA. The culture supernatants were collected, filtered through a Millipore membrane (pore size $0.45 \mu \mathrm{m}$, Sarstedt), and stored at $-20{ }^{\circ} \mathrm{C}$ until used. Five microliters of appropriate dilutions of culture supernatants or biological fluids were added to $45 \mu \mathrm{L}$ of DCAA inoculated with the biosensor strain (final $\mathrm{OD}_{600}=0.25$ ). Microtiter plates were incubated at $25^{\circ} \mathrm{C}$, and $\mathrm{OD}_{600}$ and LCPS were measured after $3.5 \mathrm{~h}$ using a Tecan Spark $10 \mathrm{M}$ multilabel plate reader. A calibration curve was generated with purified $\mathrm{PCH}$ at known concentrations $(5-320 \mathrm{nM})$ and used to calculate the concentration of PCH in each sample.
Detection of PCH and Siderophores on Agar Plates. Single colonies of different $P$. aeruginosa strains (listed in Table S1) were cultured for $8 \mathrm{~h}$ in $\mathrm{LB}$ at $37^{\circ} \mathrm{C}$. Bacteria were washed in saline, diluted to $\mathrm{OD}_{600}=0.1$, and $5 \mu \mathrm{L}$ of each bacterial suspension was spotted onto casamino acid (CAA) agarose plate ( $5 \mathrm{~g} / \mathrm{L}$ CAA and 15 $\mathrm{g} / \mathrm{L}$ agarose). After $24 \mathrm{~h}$ incubation at $37{ }^{\circ} \mathrm{C}$, PVD production was detected under UV light, and cells were killed through exposure to chloroform vapors for $15 \mathrm{~min}$. Plates were then subsequently overlaid with CAA soft agarose ( $5 \mathrm{~g} / \mathrm{L}$ casamino acids, Difco; $7.5 \mathrm{~g} / \mathrm{L}$ agarose Bio-Rad $)$ containing the biosensor strain $\left(\mathrm{OD}_{600}=0.5\right)$. After incubation at $37^{\circ} \mathrm{C}$ for $1 \mathrm{~h}$, plates were visualized with a ChemiDoc XRS+ Imaging System (Bio-Rad), using a $3 \mathrm{~min}$ exposure time.

\section{RESULTS AND DISCUSSION}

Design and Construction of a PCH-Responsive Whole Cell-Based Biosensor. To generate a biosensor capable of quantifying $\mathrm{PCH}$ at the nanomolar level, the luxCDABE operon, encoding the luciferase enzyme from the bacterium Photorhabdus luminescens, was chosen as the reporter system, being characterized by a high signal/noise ratio and not requiring supplementation with an exogenous substrate for signal (blue photon) emission. ${ }^{51,52} \mathrm{~A}$ transcriptional fusion between the PchR-dependent PpchE promoter and the lux $C D A B E$ operon was generated and integrated in the attB neutral chromosomal site in the $P$. aeruginosa $\Delta p v d A \Delta p c h D \Delta f p v A$ triple mutant ${ }^{53}$ (Figure 1). This recipient

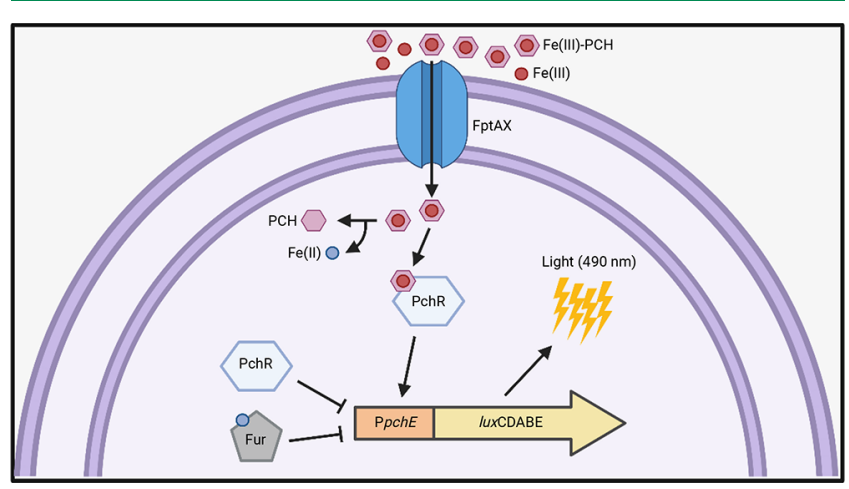

Figure 1. Schematic of the PCH-responsive whole cell-based biosensor. A transcriptional fusion between the $p c h E$ promoter (PpchE) and the luxCDABE operon was integrated in the chromosome of the $P$. aeruginosa $\Delta p v d A \Delta p c h D \Delta f p v A$ mutant. $\mathrm{Fe}(\mathrm{III})-\mathrm{PCH}$ is actively transported in the cytoplasm via FptAX, where it binds the transcriptional regulator PchR and directs the expression of the PpchE::lux fusion, eliciting bioluminescence emission. The $\mathrm{Fe}(\mathrm{II})$-bound ferric uptake regulator Fur and $\mathrm{PCH}$ unloaded PchR repress the expression of the PpchE::lux fusion. Tshaped lines represent negative control of PpchE.

strain is a siderophore null mutant, i.e., impaired in the synthesis of both PVD and PCH, and is also unable to uptake PVD due to the absence of the FpvA receptor. The inability to produce siderophores prevents $\mathrm{P} p c h \mathrm{E}$ auto-induction by endogenously synthesized PCH. Moreover, the lack of the PVD transporter FpvA prevents the entrance of exogenous PVD into the biosensor cell, thus avoiding the repression of the PpchE::lux fusion by Fe(III) delivered through the Fe(III)PVD uptake pathway. However, the $\Delta p v d A \Delta p c h D \Delta f p v A$ mutant still produces both FptA and FptX transporters, so it has no defect in $\mathrm{PCH}$ uptake from the extracellular milieu. Consequently, we predicted (i) the bioluminescence emission of the whole-cell biosensor to be dependent on the levels of exogenously added $\mathrm{PCH}$, which is transported intracellularly 


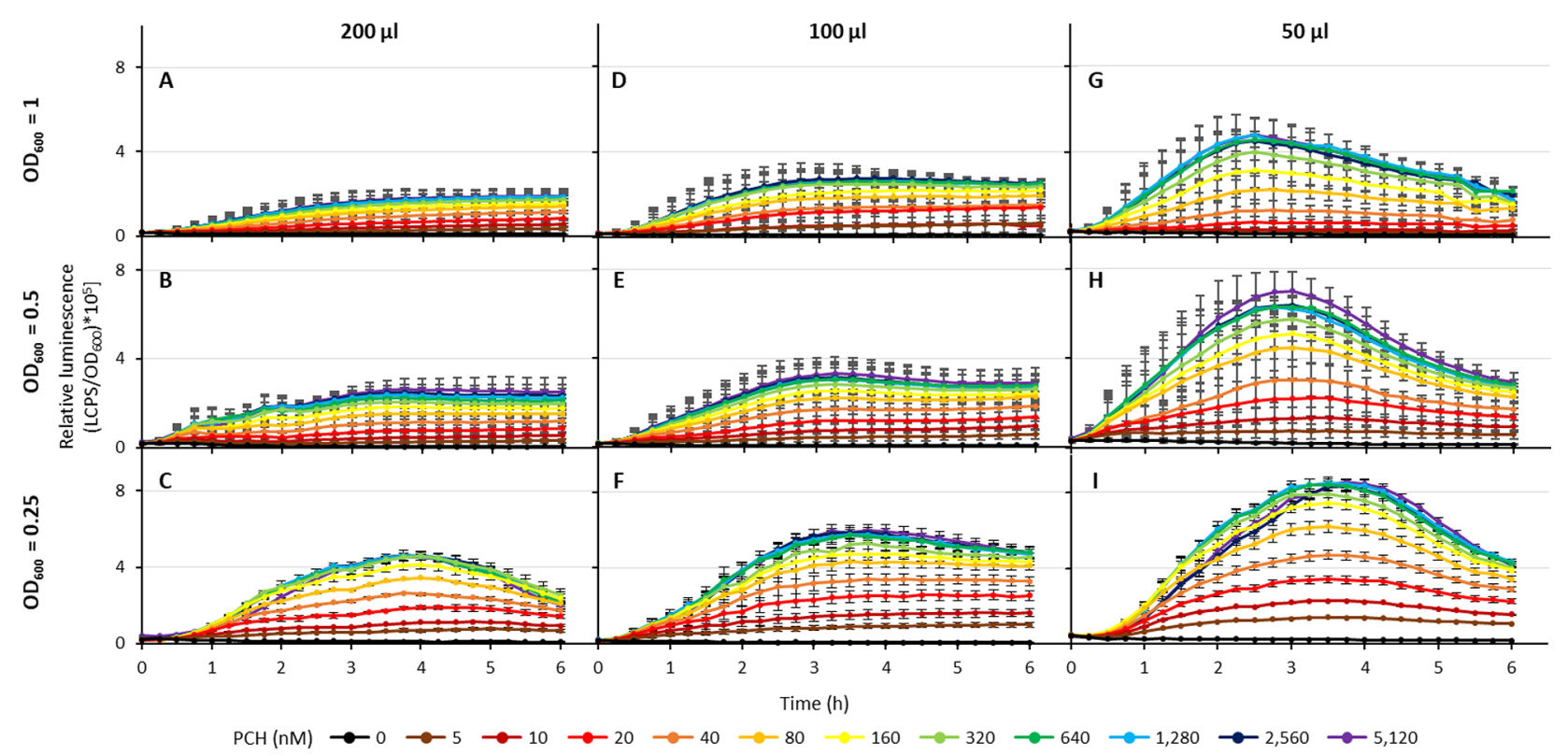

Figure 2. Effect of reporter cell density and assay volume on the biosensor response to $\mathrm{PCH}$. Relative light emission (LCPS/OD 600$)$ by the $P$. aeruginosa $\Delta p v d A \Delta p c h D \Delta f p v A$ mutant carrying the PpchE::lux fusion, in response to increasing PCH concentrations, ranging from 5 to $5120 \mathrm{nM}$. LCPS and $\mathrm{OD}_{600}$ were measured every $15 \mathrm{~min}$ for $6 \mathrm{~h}$ at $25^{\circ} \mathrm{C}$. Bacteria were inoculated at three different cell densities and three final volume combinations: (A) $200 \mu \mathrm{L}, \mathrm{OD}_{600}=1$; (B) $200 \mu \mathrm{L}, \mathrm{OD}_{600}=0.5$; (C) $200 \mu \mathrm{L}, \mathrm{OD}_{600}=0.25$; (D) $100 \mu \mathrm{L}, \mathrm{OD}_{600}=1$; (E) $100 \mu \mathrm{L}, \mathrm{OD}_{600}=0.5$; (F) $100 \mu \mathrm{L}, \mathrm{OD}_{600}=0.25$; (G) $50 \mu \mathrm{L}, \mathrm{OD}_{600}=1$; (H) $50 \mu \mathrm{L}, \mathrm{OD}_{600}=0.5$; (I) $50 \mu \mathrm{L}, \mathrm{OD}_{600}=0.25$. Data are the mean of three independent experiments $\pm \mathrm{SD}$.

and serves as inducer of the PpchE::luxCDABE promoterprobe gene fusion, and (ii) the bioluminescence emission to be proportional to the PCH concentration (Figure 1).

Experimental Setup for the Use of the Bioluminescent Whole Cell-Based Biosensor. The expression of $p c h$ (PCH biosynthesis) genes and, consequently, of the PpchE::luxCDABE reporter fusion is repressed by Fur under iron replete conditions. This is because the PpchE promoter contains a Fur-Fe(II)-binding region, which abrogates the transcriptional activity under conditions of iron availability. ${ }^{22}$

In order to prevent Fur-Fe(II)-mediated repression of the biosensor, the iron-poor medium $\mathrm{DCAA}^{36}$ was chosen for setting the operational conditions of the bioluminescent biosensor. Although iron scarcity is essential for studying the biosensor response to $\mathrm{PCH}$, too severe iron limitation imposed by DCAA $(<0.5 \mu \mathrm{M})^{36}$ would suppress the growth of a siderophore-null $P$. aeruginosa mutant. Therefore, the minimum non-limiting iron concentration allowing the $\Delta p v d A \Delta p c h D \Delta f v A$ mutant to grow similarly to the wild type, without causing complete repression of iron uptake genes, was initially investigated. To this purpose, the growth of the biosensor strain and wild-type PAO1 was monitored for 24 $\mathrm{h}$ in DCAA supplemented with increasing $\mathrm{FeCl}_{3}$ concentrations (from 0.5 to $8 \mu \mathrm{M}$ ), and PVD production by wild-type $\mathrm{PAO} 1$ was measured as an indicator of iron-repressible gene expression. $P$. aeruginosa PAO1 grew poorly in the absence of exogenously added iron, and the $\Delta p v d A \Delta p c h D \Delta f p v A$ mutant grew even less (Figure S3A,B). However, the addition of $1 \mu \mathrm{M}$ $\mathrm{FeCl}_{3}$ supported the sufficient growth of both strains without abrogating PVD production by wild-type PAO1 (Figure S3C). Therefore, biosensor cells were cultivated for $24 \mathrm{~h}$ in DCAA supplemented with $1 \mu \mathrm{M} \mathrm{FeCl}_{3}$, since this iron concentration does not shut off the expression of Fur-Fe(II)-repressible genes (i.e., pvd and pch genes).
To set the optimal experimental conditions for luminescence detection, three cell densities $\left(\mathrm{OD}_{600}=1.0 ; 0.5 ; 0.25\right)$ and three different volumes of the bacterial suspension $(200,100$, and $50 \mu \mathrm{L}$ ) were tested in a 96-well microtiter plate assay. All the experiments were performed in DCAA supplemented with purified $\mathrm{PCH}$ from $P$. aeruginosa PAO1 (concentration range 5 to $5120 \mathrm{nM}$ ), and the relative bioluminescence emission was monitored every $15 \mathrm{~min}$ for $6 \mathrm{~h}$ (Figure 2). To minimize the growth of the biosensor strain, the temperature was set at 25 ${ }^{\circ} \mathrm{C}$ during the assay. Interestingly, the lowest cell density $\left(\mathrm{OD}_{600} \simeq 0.25\right)$ and the smallest volume $(50 \mu \mathrm{L})$ provided the highest relative light emission, expressed as light counts per second (LCPS)/OD 600 of the cell suspension (Figure $2 \mathrm{I}$ ), indicating that the assay volume influences the amount of light detectable per cell and hence the biosensor response. This result can be explained by the multiple scattering effect that occurs when the concentration of particles (i.e., cells) is too high. In this case, the measured $\mathrm{OD}_{600}$ does not linearly increase with the cell number, and the Beer-Lambert law is no longer a valid approximation. In addition, the bioluminescent photons are scattered by overlying cells and are deflected away from the photodetector. ${ }^{54}$ This is because bacteria located in the upper layers shield the light signal emitted by the bacteria underneath. In fact, the higher the volume, the higher the optical path of the well, hence the light shielding by the bacterial suspension. Lowering the reaction volumes and cell densities enhanced the relative performance of the biosensor, expressed as LCPS/OD 600 . An optimal dose-dependent response of the biosensor was observed using the lowest cell density $\left(\mathrm{OD}_{600} \simeq 0.25\right)$ and the smallest assay volume $(50 \mu \mathrm{L})$ within the 5-160 nM $\mathrm{PCH}$ concentration range. $\mathrm{PCH}$ concentrations of $>160 \mathrm{nM}$ caused a moderate increase in light emission (Figure 2I). This phenomenon is likely due to the fact that $\mathrm{PCH}$ concentrations higher than $160 \mathrm{nM}$ saturate the FptA/FptX transporters and/or the transcriptional 

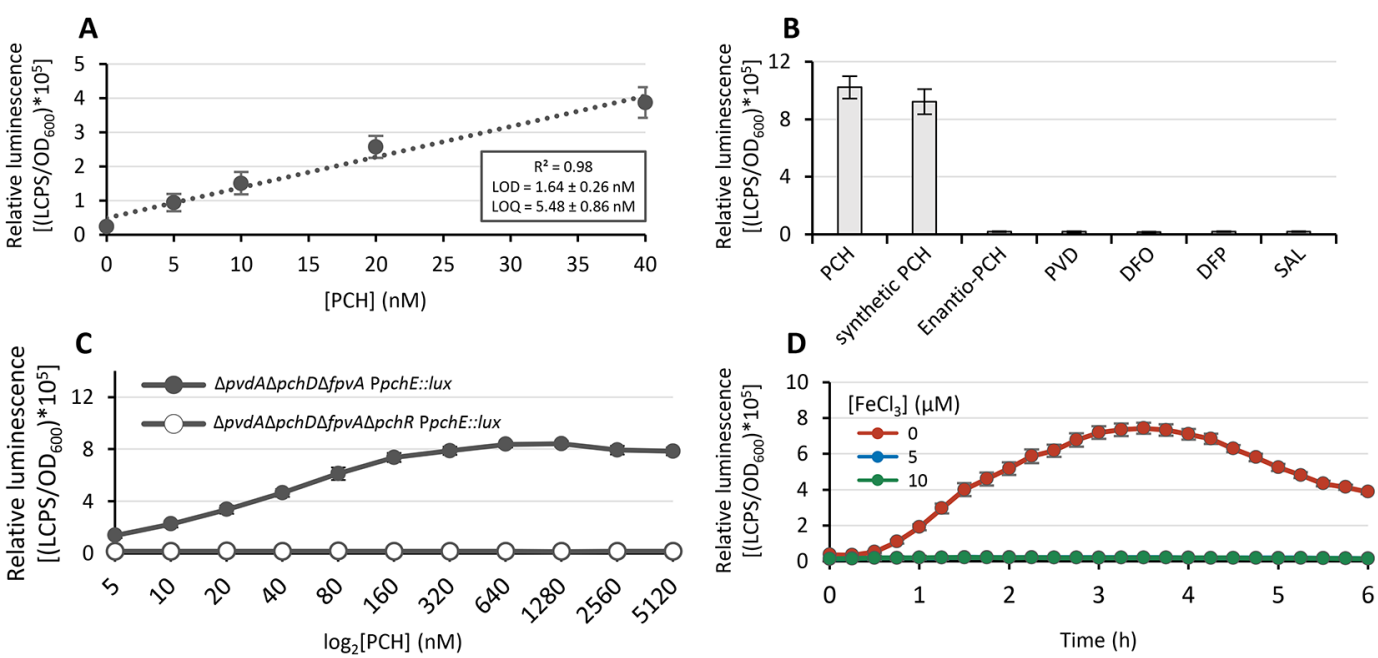

Figure 3. Biosensor response is activated by PchR and is repressed by iron. (A) Linear dose-response plot of the biosensor. Relative light emission values $\left(\mathrm{LCPS} / \mathrm{OD}_{600}\right)$ were taken after $3.5 \mathrm{~h}$ of incubation at $25{ }^{\circ} \mathrm{C}$ in the presence of increasing $\mathrm{PCH}$ concentration $(0-40 \mathrm{nM})$. The linear regression line and the $R^{2}$ value are shown. The limit of detection (LOD) and limit of quantification (LOQ) were calculated with S/N (signal/ noise ratio) values of 3 and 10, respectively. (B) Response of the biosensor to natural PCH from P. aeruginosa PAO1, synthetic PCH, enantio-PCH, pyoverdine (PVD), deferoxamine (DFO) deferiprone (DFP), and salicylate (SAL) after $3.5 \mathrm{~h}$ of incubation at $25{ }^{\circ} \mathrm{C}$. All chelators were added at the final concentration of $160 \mathrm{nM}$. (C) Relative light emission (LCPS/OD ${ }_{600}$ ) by the $P$. aeruginosa $\Delta p v d A \Delta p c h D \Delta f p d$ mutant carrying the PpchE::lux fusion (black circle) and by the P. aeruginosa $\Delta p v d A \Delta p c h D \Delta f p v A \Delta p c h R$ mutant carrying the PpchE::lux fusion (white circle) in response to increasing $\mathrm{PCH}$ concentrations $\left(5\right.$ to $5120 \mathrm{nM}$ ) after $3.5 \mathrm{~h}$ of incubation at $25^{\circ} \mathrm{C}$. (D) Relative light emission $\left(\mathrm{LCPS} / \mathrm{OD}_{600}\right)$ by the $P$. aeruginosa $\Delta p v d A \Delta p c h D \Delta f p v A$ mutant carrying the PpchE::lux fusion in response to $160 \mathrm{nM} \mathrm{PCH}$ in the presence of $5 \mu \mathrm{M}$ (square), $10 \mu \mathrm{M}$ (triangle), or without (circle) $\mathrm{FeCl}_{3}$. LCPS and $\mathrm{OD}_{600}$ were measured every 15 min for $6 \mathrm{~h}$ at $25{ }^{\circ} \mathrm{C}$. Data are the mean of three independent experiments $\pm \mathrm{SD}$.

regulator PchR. Under these conditions, the $\Delta p v d A \Delta p c h D \Delta f p v A$ PpchE::lux biosensor rapidly responded to exogenous $\mathrm{PCH}$, attaining the maximum relative light emission in 3 to $3.5 \mathrm{~h}$ after the addition of $\mathrm{PCH}$ (Figure 2I). No significant evaporation of the biosensor suspension medium (i.e., volume reduction) was noticed during the experimental time course.

Bioluminescent Cell-Based Biosensor Selectively Responds to PCH, Requires PchR, and Is Repressed by Iron. Since the maximum light emission of the $\Delta p v d A \Delta p c h D \Delta f p v A$ PpchE::lux biosensor was observed $3.5 \mathrm{~h}$ after the addition of $\mathrm{PCH}$, the limit of detection (LOD) and the limit of quantification (LOQ) were determined at this time point. A linear dose-response relationship $\left(R^{2}=0.98\right)$ in the 5-40 $\mathrm{nM}$ range of $\mathrm{PCH}$ concentration was observed (Figure $3 \mathrm{~A})$. Within this $\mathrm{PCH}$ concentration range, the LOD and LOQ values were $1.64 \pm 0.26$ and $5.48 \pm 0.86 \mathrm{nM}$, respectively (Figure 3A). These analytical performances represent a significant advance over previous $\mathrm{PCH}$ quantification methods, which required large sample volumes $(\mathrm{mL})^{36,42,55}$ and eventual concentration after solvent extraction ${ }^{36,42}$ and exhibited sensitivity in the $\mu \mathrm{M} \mathrm{PCH}$ range. ${ }^{11}$ To investigate the selectivity of the $\Delta p v d A \Delta p c h D \Delta f p v A$ P pchE::lux biosensor, the luminescence emission was measured upon the addition of several iron-chelating compounds, using the standard test conditions $\left(\mathrm{OD}_{600} \simeq 0.25 ; 50 \mu \mathrm{L}\right.$ volume; $\left.3.5 \mathrm{~h} ; 25{ }^{\circ} \mathrm{C}\right)$. Purified PCH from $P$. aeruginosa PAO1 and chemically synthetized $\mathrm{PCH}$ were included as controls. Each ironchelating compound (listed in Table S3) was added at 160 $\mathrm{nM}$. As expected, the bioluminescence emission induced by the chemically synthesized $\mathrm{PCH}$ was similar to that of the native $\mathrm{PCH}$ extracted from $P$. aeruginosa culture supernatants (Figure 3B). Conversely, in the presence of chemically synthesized enantio- $\mathrm{PCH}$, a $\mathrm{PCH}$ diastereoisomer was produced by
Pseudomonas protegens, ${ }^{56}$ and the bioluminescence emission was completely abrogated (Figure 3B). The inability of enantio-PCH to induce the expression of $\mathrm{PCH}$ genes in $P$. aeruginosa and consequently the biosensor response confirms that enantio- $\mathrm{PCH}$ is not recognized by $P$. aeruginosa due to the high specificity of the $\mathrm{PCH}$ translocation machinery and of the PchR-mediated gene expression. ${ }^{55}$ No response was also observed with other iron-chelating compounds, namely, PVD, deferoxamine (DFO), deferiprone (DFP), and sodium salicylate (SAL, a $\mathrm{PCH}$ precursor), further confirming the biosensor selectivity (Figure 3B). The biosensor genetic circuitry is based on the assumption that the production of $\mathrm{PCH}$ is controlled by the cytoplasmic transcriptional regulator PchR, which activates the transcription of $\mathrm{PCH}$ biosynthesis and transport genes. To define the role of PchR on the biosensor response, the $p c h R$ gene was deleted from the $\Delta p v d A \Delta p c h D \Delta f p v A$ PpchE::lux biosensor strain, and the expression of the PpchE::lux fusion was monitored using the standard assay conditions $\left(\mathrm{OD}_{600} \simeq 0.25 ; 50 \mu \mathrm{L}\right.$ volume; $3.5 \mathrm{~h}$; $25{ }^{\circ} \mathrm{C}$ concentration range). As expected, the deletion of $p c h R$ completely abrogated PCH-inducible PpchE::lux expression in the $5-5.120 \mathrm{nM} \mathrm{PCH}$ range, confirming that PchR is strictly required in $\mathrm{PCH}$ gene expression and thus for the $\mathrm{PCH}$ mediated response of the biosensor (Figure 3C).

To verify the ability of iron to repress the expression of the PpchE::lux fusion, the biosensor was exposed to $160 \mathrm{nM}$ of $\mathrm{PCH}$, in the presence of two different $\mathrm{FeCl}_{3}$ concentrations (i.e., 5 and $10 \mu \mathrm{M}$ ). The bioluminescence signal emission was completely shut off with $5 \mu \mathrm{M} \mathrm{FeCl}_{3}$ (Figure 3D).

Taken together, these results indicate that the biosensor response depends on the concentration of $\mathrm{PCH}$ and iron, in line with the regulatory mechanisms, which control $\mathrm{PCH}$ production and uptake. 

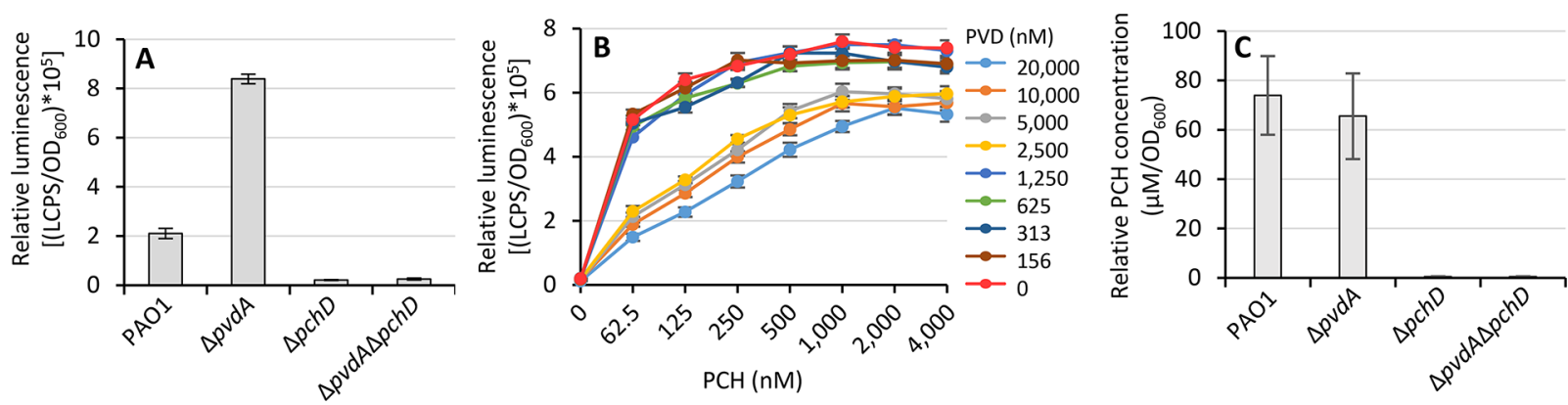

Figure 4. Factors affecting $\mathrm{PCH}$ detection in $P$. aeruginosa culture supernatants. Relative bioluminescence emission of the $P$. aeruginosa $\Delta p v d A \Delta p c h D \Delta f p v A$ PpchE::lux biosensor, in the presence of PAO1, $\Delta p v d A, \Delta p c h D$, and $\Delta p v d A \Delta p c h D$ culture supernatants obtained after a 24 h growth in DCAA (A) or in the presence of increasing concentrations of PCH (from 0.625 to $4 \mu \mathrm{M}$ ) and of PVD (from 0.625 to $20 \mu \mathrm{M})$ (B). (C) $\mathrm{PCH}$ concentrations $\left(\mu \mathrm{M} / \mathrm{OD}_{600}\right)$ in the diluted $(1: 1024)$ supernatants of the indicated P. aeruginosa strains grown for $24 \mathrm{~h}$ in DCAA. Data are representative of three independent experiments \pm SD.

PVD Interference with PCH Measurement. Several studies in animal models and humans showed that $\mathrm{PCH}$ biosynthesis and uptake genes are expressed during $P$. aeruginosa infection, ${ }^{25-29}$ though the presence of $\mathrm{PCH}$ could be detected fluorometrically in a few CF sputum samples. ${ }^{11,26}$ Fluorescence spectroscopy can detect PCH concentrations of $>1 \mu \mathrm{M}$, and therefore, with this method, it is not possible to detect $\mathrm{PCH}$ in $P$. aeruginosa isolates, which produce lower $\mathrm{PCH}$ concentrations (i.e., $<1 \mu \mathrm{M}) .^{11}$ Moreover, $\mathrm{PCH}$ fluorescence is quenched upon $\mathrm{Fe}$ (III) binding, ${ }^{57}$ implying that the $\mathrm{Fe}(\mathrm{III})-\mathrm{PCH}$ complex escapes fluorometric detection. Another commonly used procedure for $\mathrm{PCH}$ quantification entails solvent extraction and purification by HPLC. ${ }^{39}$ Both these methods are affected by significant analyte loss and unavoidably underestimate the actual concentration of $\mathrm{PCH}$ produced by $P$. aeruginosa.

The ability of the biosensor to specifically and rapidly respond to low $\mathrm{PCH}$ concentrations encouraged its use for direct $\mathrm{PCH}$ quantification in $P$. aeruginosa culture supernatants. Calibration of the biosensor can easily be obtained with commercially available PCH (Santa Cruz Biotechnology Inc., CA). To this purpose, the supernatants of wild-type PAO1 and $\Delta p v d A$ and $\Delta p c h D$ single and double mutants were collected after $24 \mathrm{~h}$ of growth in the iron-poor medium DCAA, and the biosensor bioluminescence emission was measured. As expected, no bioluminescence emission was recorded in culture supernatants of $\mathrm{PCH}$-defective mutants, indicating that no compound other than $\mathrm{PCH}$ can trigger the biosensor (Figure 4A). Surprisingly, the bioluminescence emission of the PAO1 culture supernatant was much lower than that of the $p v d A$ mutant (Figure 4A). This result is in contrast with previous data showing that wild-type PAO1 and PVD defective mutants produce a similar amount of $\mathrm{PCH}$ under iron-limited conditions $^{24}$ and suggests that high PVD levels can interfere with the biosensor response. To verify this hypothesis, $\mathrm{PCH}$ was extracted from the supernatant of PAO1, $\Delta p v d A, \Delta p c h D$, and $\Delta p v d A \Delta p c h D$ and analyzed by TLC. The PCH spot of PAO1 was quantitatively similar that of the $p v d A$ mutant (Figure S4A), suggesting that $\mathrm{PCH}$ production in these two strains is comparable under the test conditions. Since PAO1 produces a high amount of PVD when grown in DCAA (Figure S4B), we hypothesized that PVD may hamper $\mathrm{PCH}$ measurements by chelating iron traces in the growth medium. Indeed, previous work has demonstrated that PchR binds $\mathrm{PCH}$ in its iron-loaded form, while it does not in its apo-form. ${ }^{21,58}$ Therefore, iron withholding by PVD could negatively affect
$\mathrm{PCH}$ gene expression, and consequently bioluminescence emission. To verify this hypothesis, the biosensor response was measured in the presence of increasing concentrations of purified PCH and PVD (62.5-4000 and 20-20,000 nM, respectively). The choice of using $20,000 \mathrm{nM}$ as the maximum PVD concentration derives from the experimental observation that $P$. aeruginosa $\mathrm{PAO} 1$ produces $\approx 200 \mu \mathrm{M}$ PVD in DCAA culture supernatants (Figure S4B) and that a 1:10 dilution (i.e., $5 \mu \mathrm{L}$ of culture supernatants added to $45 \mu \mathrm{L}$ of biosensor suspension) is used for the assay. PVD concentrations of $\geq 2500 \mathrm{nM}$ significantly reduced the biosensor luminescence emission (Figure 4B), even in the presence of elevated $\mathrm{PCH}$ concentrations. Conversely, PVD concentrations of $\leq 1250 \mathrm{nM}$ had a negligible effect on the biosensor luminescence emission at all PCH concentrations tested. The above findings suggest that an appropriate dilution of $P$. aeruginosa culture supernatants can overcome PVD interference in the $\mathrm{PCH}$ biosensor assay. To corroborate these results, the culture supernatants of wild-type PAO1 and $\Delta p v d A$ and $\Delta p c h D$ single and double mutants were serially diluted, and the bioluminescence emission of the $\Delta p v d A \Delta p c h D \Delta f p v A$ PpchE::lux biosensor was measured after $3.5 \mathrm{~h}$ at $25{ }^{\circ} \mathrm{C}$. Interestingly, the luminescence emission progressively increased with serial dilution of the PAO1 supernatant, reaching the same values of the PVD-deficient $\Delta p v d A$ mutant at 1:32 dilution (Figure $\mathrm{S} 5 \mathrm{~A}$ ). Moreover, the biosensor luminescence emission in the presence of the $\Delta p v d A$ mutant supernatant was nearly constant up to the 1:32 dilution, suggesting that $\mathrm{PCH}$ levels in supernatants of the PVD-defective mutant exceeded the upper detection limit of the biosensor, resulting in its saturation.

The above results indicate that an appropriate dilution of culture supernatants is mandatory for $\mathrm{PCH}$ quantification. To calculate the concentration of $\mathrm{PCH}$ produced by $P$. aeruginosa, $1: 256,1: 512$, and $1: 1024$ dilutions were used, and the $\mathrm{PCH}$ concentration was calculated by using a standard calibration curve (Figure S5B). Interestingly, the $\mathrm{PCH}$ concentrations estimated by using the three different dilutions gave comparable results (Figure S5C), as expected for $\mathrm{PCH}$ concentrations below the biosensor saturation point (i.e., 160 $\mathrm{nM}$, Figure 2I and Figure 3C). Therefore, the lowest sample dilution (1:1024) was selected for further experiments (see also the Supporting Information, text S1). By diluting the supernatant, the $\mathrm{PCH}$ concentrations determined for PAO1 and the $\Delta p v d A$ mutant culture supernatants $\left(\approx 70 \mu \mathrm{M} / \mathrm{OD}_{600}\right)$ were in line with previous experiments (Figure 4C) and literature data. ${ }^{59}$ 

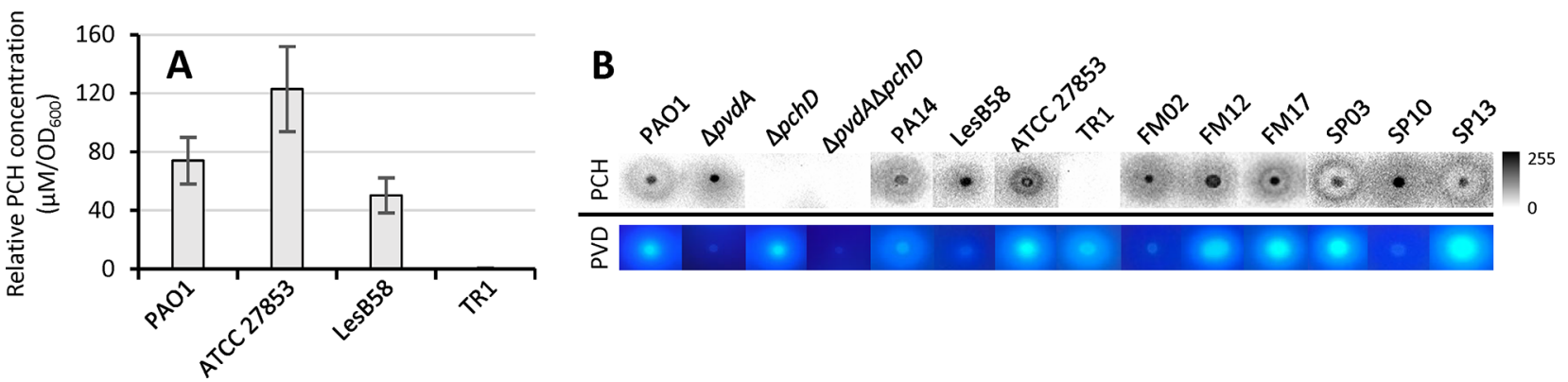

Figure 5. Bioassays for $\mathrm{PCH}$ detection in liquid and solid media. (A) $\mathrm{PCH}$ concentrations $\left(\mu \mathrm{M} / \mathrm{OD}_{600}\right)$ in the culture supernatants of $P$. aeruginosa strains PAO1, ATCC 27853, LesB58, and TR1 grown in DCAA for $24 \mathrm{~h}$. Supernatants were 1:1024 diluted, and PCH concentration was calculated using a PCH calibration curve, as outlined in the Supporting Information, text S1. Data are representative of three independent experiments \pm SD. (B) Top: qualitative detection of $\mathrm{PCH}$ production on CAA agarose plates, as outlined in the Supporting Information, text S2. P. aeruginosa strains were spotted on CAA agarose plates, grown for $24 \mathrm{~h}$ at $37^{\circ} \mathrm{C}$, and killed by chloroform vapor. Then, CAA agarose plates were overlaid with the $P$. aeruginosa $\Delta p v d A \Delta p c h D \Delta f p v A$ PpchE::lux biosensor strain and incubated for $1 \mathrm{~h}$ at $37^{\circ} \mathrm{C}$. The $\mathrm{PCH}$ grey halo was detected using a ChemiDoc XRS+ Imaging System (Bio-Rad). The gray scale denotes pixel intensity. Bottom: PVD production by the P. aeruginosa strain, prior to the biosensor overlay, detected as fluorescence emission upon UV light exposure. Images are representative of one of several independent tests providing similar results.
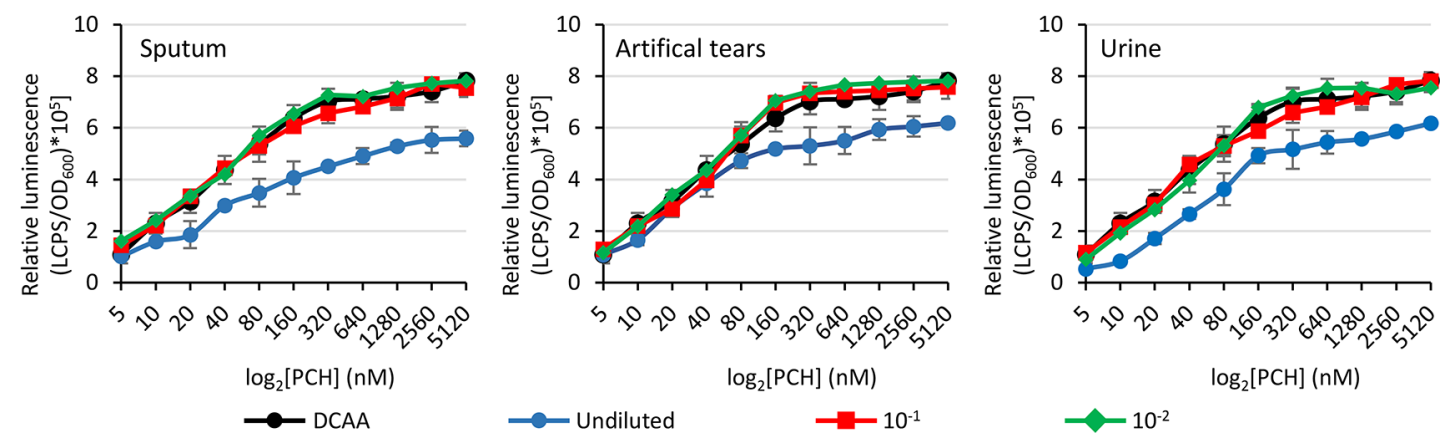

Figure 6. Biosensor response to $\mathrm{PCH}$-spiked biological fluids. Relative light emission (LCPS/OD 600 ) of the P. aeruginosa $\Delta p v d A \Delta p c h D \Delta f p v A$ PpchE::lux biosensor in response to increasing concentrations of PCH (5 to $5120 \mathrm{nM})$ in undiluted and diluted $\left(10^{-1}\right.$ and $\left.10^{-2}\right)$ biological fluids, after $3.5 \mathrm{~h}$ of incubation at $25{ }^{\circ} \mathrm{C}$. Each value represents the mean $\pm \mathrm{SD}$ of three independent experiments.

PCH Quantification in P. aeruginosa Clinical Strains and Biological Fluids. To check the ability of the biosensor to measure $\mathrm{PCH}$ levels produced by clinical $P$. aeruginosa strains, $P$. aeruginosa ATCC $27853^{60}$ and the Liverpoolepidemic strain LesB58 ${ }^{61}$ were preliminarily tested. $P$. aeruginosa ATCC 27853 and LesB58 produce different PVD types (i.e., type II and III PVD, respectively) and release quite different PVD levels in the medium (Figure S4B). P. aeruginosa strains were cultured for $24 \mathrm{~h}$ in DCAA, and the supernatants were diluted. The biosensor response to the supernatant of ATCC 27853 was similar to that observed with PAO1, showing biosensor saturation and PVD interference for $\leq 1: 32$ supernatant dilution. Contrarily, the supernatant of LesB58 determined an initial increase (2-fold dilution) of bioluminescence emission, which remained constant up to the 64-fold dilution (Figure S5D). The different response profile can be ascribed to the different PVD concentrations in the supernatants of two test strains (Figure S4B). Indeed, the amount of PVD produced by PAO1 and ATCC 27853 under iron-poor conditions is almost the same $(\sim 200 \mu \mathrm{M})$, while the PVD concentration in the LesB58 supernatant is 10-fold lower (Figure S4B). These findings further corroborate the need of eliminating PVD interference by diluting the supernatant prior to $\mathrm{PCH}$ measurement. On this basis, to calculate the exact concentration of $\mathrm{PCH}$ produced by PAO1, ATCC 27853, and LesB58, culture supernatants were diluted 1:1024, and $5 \mu \mathrm{L}$ of each supernatant were used for the assay, as recommended in the Supporting Information, text S1. Preliminary dilution lowers the PVD concentration to $<40 \mathrm{nM}$, thereby preventing any interference of PVD with biosensor response to $\mathrm{PCH}$ (Figure 4B). The clinical $P$. aeruginosa isolate TR1 was included as a negative control, being a natural $\mathrm{PCH}$-defective mutant. ${ }^{62}$ Interestingly, $\mathrm{PCH}$ production was slightly lower in P. aeruginosa LesB58 than in ATCC 27853 and PAO1, while no $\mathrm{PCH}$ was detected in the supernatant of the $\mathrm{PCH}$-negative strain TR1 (Figure 5A). Altogether, these results indicate that, with an appropriate setting (Supporting Information, text S1), the biosensor is a valuable tool to quantify $\mathrm{PCH}$ production by $P$. aeruginosa clinical isolates.

Lastly, the newly generated whole-cell biosensor was adapted to generate a rapid screening system of $\mathrm{PCH}$ producing $P$. aeruginosa strains on solid media. To this aim, several $P$. aeruginosa strains (listed in Table S1) were spotinoculated on CAA agarose plates and grown at $37^{\circ} \mathrm{C}$ for $24 \mathrm{~h}$ until $\sim 3 \mathrm{~mm}$ colonies became visible. Colonies were inspected under UV light exposure to detect PVD production (blue halo), and then bacteria were killed with chloroform vapors. Thereafter, a thin $(\sim 1 \mathrm{~mm})$ agarose layer containing the $\Delta p v d A \Delta p c h D \Delta f p v A$ P pchE::lux biosensor was overlaid onto the test colonies and bioluminescence emission was detected after $1 \mathrm{~h}$ incubation at $37^{\circ} \mathrm{C}$. To validate the plate-based screening system, wild-type $P$. aeruginosa $\mathrm{PAO} 1$ and $\mathrm{PCH}$ and/ or PVD defective mutants were tested. Noteworthy, the same signal was registered for wild-type $P$. aeruginosa $\mathrm{PAO} 1$ and 
PVD-null mutant $\Delta p v d A$, (Figure 5B), while no light emission was observed for $\Delta p c h D, \Delta p v d A \Delta p c h D$, and TR1 PCH-null mutants (Figure 5B). Although with some differences, probably due to growth rate variations and PVD production levels (Figure 5B, bottom), all clinical strains tested positive for $\mathrm{PCH}$ production (Figure $5 \mathrm{~B}$ ).

The $\mathrm{PCH}$ plate assay was then applied to the screening of 98 $P$. aeruginosa clinical isolates from $\mathrm{CF}$ patients at different stages of lung infection. The vast majority of isolates produced both siderophores (Table S4); PVD- and PCH-negative isolates were only 16.3 and $7.1 \%$, respectively, with two isolates testing double-negative.

The biosensor performances were also tested using sputum, artificial tears, and urine as input samples, upon spiking with known $\mathrm{PCH}$ concentrations ( 5 to $5120 \mathrm{nM}$ ). While undiluted fluids significantly reduced the biosensor response, negligible interference was observed for 10- and 100-fold diluted fluids (Figure 6).

Interestingly, transcription of pch biosynthetic genes was previously demonstrated in the majority of CF sputa, though $\mathrm{PCH}$ was detected in only $13 \%$ of them, likely due to the poor sensitivity of the $\mathrm{PCH}$ detection method $(\sim 1 \mu \mathrm{M}) .{ }^{26}$ Here, pilot testing of sputa from eight anonymous CF patients revealed that $\mathrm{PCH}$ was detectable in six of them (range $86.9 \pm$ 4.6-24,390.0 $\pm 91.2 \mathrm{nM}$ ), showing an excellent correlation between the presence of $\mathrm{PCH}$ and $P$. aeruginosa culturepositivity of sputa (Table S5).

Altogether, these results indicate that the $\Delta p v d A \Delta p c h D \Delta f p$ $v A$ PpchE::lux biosensor is suitable for $\mathrm{PCH}$ quantification in both $P$. aeruginosa culture supernatants and biological fluids and can be used for the rapid screening of $\mathrm{PCH}$-producing $P$. aeruginosa isolates on a solid medium (Supporting Information, text S2).

\section{CONCLUSIONS}

In summary, we generated a whole cell-based biosensor for $\mathrm{PCH}$ quantification and tested its proficiency under laboratory conditions. The biosensor specificity is guaranteed by the unique selectivity of the $\mathrm{PCH}$ transport machinery and the PchR activator of the PpchE::lux reporter fusion. In fact, both the FptA receptor and the PchR regulator are strictly $\mathrm{PCH}$ selective. ${ }^{58,63}$ Accordingly, evidence was provided that the biosensor does not respond to $\mathrm{PCH}$ stereoisomers or precursors, as well as to a variety of iron-chelating compounds, excluding the possibility of false positive readouts.

Two main factors, namely, iron and PVD carryover in the test sample, were shown to interfere with the biosensor performances. Both factors, however, do not undermine the biosensor validity by virtue of the extremely high sensitivity of the assay (lower detection limit $=1.64 \pm 0.26 \mathrm{nM} \mathrm{PCH}$ ), which requires the sample to be diluted several fold $\left(\cong 10^{-3}\right)$ prior to testing, so that interference by iron and PVD would be negligible. It should also be taken into account that $\mathrm{PCH}$ is produced by $P$. aeruginosa only under conditions of severe iron limitation $[<5 \mu \mathrm{M} \mathrm{Fe}(\mathrm{III})]^{40}$ implying that the presence of sufficient $(\geq 5 \mu \mathrm{M})$ iron levels in biological samples would be incompatible with $\mathrm{PCH}$ production by $P$. aeruginosa. In practice, considering that the concentration of secreted $\mathrm{PCH}$ is extremely variable depending on the $P$. aeruginosa strain and growth conditions (from $\sim 800,000$ to $\sim 1000 \mathrm{nM}$ in optimized laboratory media and CF sputa, respectively), ${ }^{11,34}$ appropriate serial dilutions of the sample should be made to adjust the $\mathrm{PCH}$ concentration in the linear response range of the biosensor (5-40 nM; Figure 3A). Of note, a calibration curve can be easily prepared using pure $\mathrm{PCH}$, which is commercially available.

The luminescent biosensor offers several advantages over previous $\mathrm{PCH}$ detection and/or quantification methods, which rely on chromatographic or spectrophotometric analysis of partially purified organic extracts. Briefly, (i) the assay protocol is straightforward and allows $\mathrm{PCH}$ to be quantified in $3.5 \mathrm{~h}$ with negligible sample handling; (ii) up to 28 samples can contemporarily be tested in triplicate using a single 96-well microplate, also including standard samples for system calibration; (iii) the microtiter plate format would allow the assay to be scaled down to a smaller format for higher throughput (e.g., using 384-well microplates) and is amenable to automation (e.g., using automatic dispensers); (iv) once dispensed with the reporter strain, the microtiter plates can be stored frozen at $-80{ }^{\circ} \mathrm{C}$ for months with negligible loss of the assay performances (Figure S6); (v) the assay combines high sensitivity (LOQ in the $\mathrm{nM}$ PCH range) with simplicity, since the luciferase-based reporter system is characterized by a high signal/noise ratio and does not require an exogenous substrate for signal emission. Bioluminescence background levels in living cells are extremely low, making bioluminescence up to 50 times more sensitive than fluorescence, which would be impracticable in testing the intrinsically fluorescent Pseudomonas species. ${ }^{52,64}$ Moreover, $P$. luminescens luciferase is endowed with remarkable chemical and physical stability. ${ }^{65}$

The inclusion of $P$. aeruginosa into the list of risk group 2 bacterial pathogens could represent a limitation to the use of the luminescent biosensor in biosafety level 1 laboratories. However, the $P$. aeruginosa PAO1 $\Delta p v d A \Delta p c h D \Delta f p v A$ mutant carries stable genetic knock-outs of both $\mathrm{PCH}$ and PVD biosynthesis genes, together with a deletion of the PVD receptor gene. Altogether, these mutations impair iron uptake and result in an avirulent phenotype in animal models of infections, ${ }^{24,66,67}$ downgrading the risk associated with biosensor manipulation.

In conclusion, the $\Delta p v d A \Delta p \operatorname{chD} \Delta f p v A$ PpchE::lux whole cell-based biosensor represents an innovative tool to detect and quantify the $\mathrm{PCH}$ siderophore. The preliminary setup of the test conditions allows the fast, easy, accurate, and cost-effective determination of nanomolar $\mathrm{PCH}$ concentrations in $P$. aeruginosa liquid cultures and biological fluids, as well as the qualitative screening of $\mathrm{PCH}$-producing $P$. aeruginosa colonies on an agar plate, hopefully facilitating future investigations on the role of $\mathrm{PCH}$ in the pathogenesis of $P$. aeruginosa infection.

\section{ASSOCIATED CONTENT}

\section{(s) Supporting Information}

The Supporting Information is available free of charge at https://pubs.acs.org/doi/10.1021/acssensors.1c01023.

Supplementary methods, figures, tables, and description of the analytical protocol (PDF)

\section{AUTHOR INFORMATION}

\section{Corresponding Authors}

Daniela Visaggio - Department of Science, Roma Tre University, Rome 00146, Italy; Santa Lucia Fundation IRCCS, Rome 00179, Italy; Email: daniela.visaggio@ uniroma3.it

Paolo Visca - Department of Science, Roma Tre University, Rome 00146, Italy; Santa Lucia Fundation IRCCS, Rome 
00179, Italy; ๑ orcid.org/0000-0002-6128-7039;

Email: paolo.visca@uniroma3.it

\section{Authors}

Mattia Pirolo - Department of Science, Roma Tre University, Rome 00146, Italy; Present Address: Department of Veterinary and Animal Sciences, University of Copenhagen, DK-1165 Frederiksberg, Denmark

Emanuela Frangipani - Department of Biomolecular Sciences, University of Urbino Carlo Bo, Urbino 61029, Italy; (-) orcid.org/0000-0001-5619-7912

Massimiliano Lucidi - Department of Science, Roma Tre University, Rome 00146, Italy

Raffaella Sorrentino - Department of Molecular Medicine and Medical Biotechnology, University of Naples Federico II, Naples 80138, Italy

Emma Mitidieri - Department of Molecular Medicine and Medical Biotechnology, University of Naples Federico II, Naples 80138, Italy

Francesca Ungaro - Department of Pharmacy, University of Naples Federico II, Naples 80131, Italy; $\odot$ orcid.org/00000003-0850-9533

Andrea Luraghi - Department of Biotechnology and Biosciences, University of Milano-Bicocca, Milan 20126, Italy

Francesco Peri - Department of Biotechnology and Biosciences, University of Milano-Bicocca, Milan 20126,

Italy; 10 orcid.org/0000-0002-3417-8224

Complete contact information is available at: https://pubs.acs.org/10.1021/acssensors.1c01023

\section{Author Contributions}

E.F. and P.V. conceived and designed the study. D.V., M.P., M.L., A.L., and E.M. performed the experiments. E.F., R.S., F.U., F.P., and P.V. analyzed the results. D.V., E.F., F.P., and P.V. wrote the manuscript. All authors have given approval to the final version of the manuscript.

\section{Author Contributions}

${ }^{\ddagger}$ D.V. and M.P. contributed equally to this work.

\section{Funding}

This work was supported by grants FFC\#21/2015 and FFC\#18/2017 from the Italian Cystic Fibrosis Research Foundation, and grant PRIN 2017 Prot. 20177J5Y3P from the Italian Ministry of Education, University and Research (MIUR), to P.V.

\section{Notes}

The authors declare no competing financial interest.

\section{ABBREVIATIONS}

CAA, casamino acids; DCAA, deferrated casamino acids; DFP, deferiprone; DFO, deferoxamine; DMSO, dimethyl sulfoxide; Fur, ferric uptake regulator protein; HPLC, high-performance liquid chromatography; LB, Luria-Bertani broth; LCPS, light counts per second; LOD, limit of detection; LOQ limit of quantification; PVD, pyoverdine; PCH, pyochelin; S, slope of calibration curve; SAL, salicylate; $\mathrm{S} / \mathrm{N}$, signal/noise ratio; $\mathrm{SD}$, standard deviation; TLC, thin layer chromatography

\section{REFERENCES}

(1) Ganz, T. Iron in Innate Immunity: Starve the Invaders. Curr. Opin. Immunol. 2009, 21, 63-67.

(2) Carver, P. L. The Battle for Iron between Humans and Microbes. Curr. Med. Chem. 2018, 25, 85-96.
(3) Krewulak, K. D.; Vogel, H. J. Structural Biology of Bacterial Iron Uptake. Biochim. Biophys. Acta, Biomembr. 2008, 1778, 1781-1804.

(4) Lamont, I. L.; Konings, A. F.; Reid, D. W. Iron Acquisition by Pseudomonas aeruginosa in the Lungs of Patients with Cystic Fibrosis. BioMetals 2009, 22, 53-60.

(5) Lyczak, J. B.; Cannon, C. L.; Pier, G. B. Lung Infections Associated with Cystic Fibrosis. Clin. Microbiol. Rev. 2002, 15, 194222.

(6) Cox, C. D.; Adams, P. Siderophore Activity of Pyoverdin for Pseudomonas aeruginosa. Infect. Immun. 1985, 48, 130-138.

(7) Liu, P. V.; Shokrani, F. Biological Activities of Pyochelins: IronChelating Agents of Pseudomonas aeruginosa. Infect. Immun. 1978, 22, 878-890.

(8) Albrecht-Gary, A. M.; Blanc, S.; Rochel, N.; Ocacktan, A. Z.; Abdallah, M. A. Bacterial Iron Transport: Coordination Properties of Pyoverdin PaA, a Peptidic Siderophore of Pseudomonas aeruginosa. Inorg. Chem. 1994, 33, 6391-6402.

(9) Visca, P.; Imperi, F.; Lamont, I. L. Pyoverdine Siderophores: From Biogenesis to Biosignificance. Trends Microbiol. 2007, 15, 2230.

(10) Haas, B.; Kraut, J.; Marks, J.; Zanker, S. C.; Castignetti, D. Siderophore Presence in Sputa of Cystic Fibrosis Patients. Infect. Immun. 1991, 59, 3997-4000.

(11) Martin, L. W.; Reid, D. W.; Sharples, K. J.; Lamont, I. L. Pseudomonas Siderophores in the Sputum of Patients with Cystic Fibrosis. BioMetals 2011, 24, 1059-1067.

(12) Ankenbauer, R. G.; Cox, C. D. Isolation and Characterization of Pseudomonas aeruginosa Mutants Requiring Salicylic Acid for Pyochelin Biosynthesis. J. Bacteriol. 1988, 170, 5364-5367.

(13) Serino, L.; Reimmann, C.; Baur, H.; Beyeler, M.; Visca, P.; Haas, D. Structural Genes for Salicylate Biosynthesis from Chorismate in Pseudomonas aeruginosa. Mol. Gen. Genet. 1995, 249, 217-228.

(14) Serino, L.; Reimmann, C.; Visca, P.; Beyeler, M.; Chiesa, V. D.; Haas, D. Biosynthesis of Pyochelin and Dihydroaeruginoic Acid Requires the Iron-Regulated pchDCBA Operon in Pseudomonas aeruginosa. J. Bacteriol. 1997, 179, 248-257.

(15) Schlegel, K.; Taraz, K.; Budzikiewicz, H. The Stereoisomers of Pyochelin, a Siderophore of Pseudomonas aeruginosa. BioMetals 2004, 17, 409-414.

(16) Brandel, J.; Humbert, N.; Elhabiri, M.; Schalk, I. J.; Mislin, G. L.; Albrecht-Gary, A. M. Pyochelin, a Siderophore of Pseudomonas aeruginosa: Physicochemical Characterization of the Iron(III), Copper(II) and Zinc(II) complexes. Dalton Trans. 2012, 41, 28202834.

(17) Ronnebaum, T. A.; Lamb, A. L. Nonribosomal Peptides for Iron Acquisition: Pyochelin Biosynthesis as a Case Study. Curr. Opin. Struct. Biol. 2018, 53, 1-11.

(18) Cunrath, O.; Gasser, V.; Hoegy, F.; Reimmann, C.; Guillon, L.; Schalk, I. J. A Cell Biological View of the Siderophore Pyochelin Iron Uptake Pathway in Pseudomonas aeruginosa. Environ. Microbiol. 2015, 17, 171-185.

(19) Reimmann, C. Inner-Membrane Transporters for the Siderophores Pyochelin in Pseudomonas aeruginosa and Enantio-Pyochelin in Pseudomonas fluorescens Display Different Enantioselectivities. Microbiology 2012, 158, 1317-1324.

(20) Heinrichs, D. E.; Poole, K. PchR, a Regulator of Ferripyochelin Receptor Gene (FptA) Expression in Pseudomonas aeruginosa, Functions Both as an Activator and as a Repressor. J. Bacteriol. 1996, 178, 2586-2592.

(21) Michel, L.; González, N.; Jagdeep, S.; Nguyen-Ngoc, T.; Reimmann, C. PchR-Box Recognition by the AraC-Type Regulator PchR of Pseudomonas aeruginosa Requires the Siderophore Pyochelin as an Effector. Mol. Microbiol. 2005, 58, 495-509.

(22) Reimmann, C.; Serino, L.; Beyeler, M.; Haa, D. Dihydroaeruginoic Acid Synthetase and Pyochelin Synthetase, Products of the pchEF, Are Induced by Extracellular Pyochelin in Pseudomonas aeruginosa. Microbiology 1998, 144, 3135-3148.

(23) Palmer, L. D.; Skaar, E. P. Transition Metals and Virulence in Bacteria. Annu. Rev. Genet. 2016, 50, 67-91. 
(24) Minandri, F.; Imperi, F.; Frangipani, E.; Bonchi, C.; Visaggio, D.; Facchini, M.; Pasquali, P.; Bragonzi, A.; Visca, P. Role of Iron Uptake Systems in Pseudomonas aeruginosa Virulence and Airway Infection. Infect. Immun. 2016, 84, 2324-2335.

(25) Kim, M.; Christley, S.; Khodarev, N. N.; Fleming, I.; Huang, Y.; Chang, E.; Zaborina, O.; Alverdy, J. Pseudomonas aeruginosa Wound Infection Involves Activation of Its Iron Acquisition System in Response to Fascial Contact. J. Trauma Acute Care Surg. 2015, 78, 823-829.

(26) Konings, A. F.; Martin, L. W.; Sharples, K. J.; Roddam, L. F.; Latham, R.; Reid, D. W.; Lamont, I. L. Pseudomonas aeruginosa Uses Multiple Pathways To Acquire Iron during Chronic Infection in Cystic Fibrosis Lungs. Infect. Immun. 2013, 81, 2697-2704.

(27) Kruczek, C.; Kottapalli, K. R.; Dissanaike, S.; Dzvova, N.; Griswold, J. A.; Colmer-Hamood, J. A.; Hamood, A. N. Major Transcriptome Changes Accompany the Growth of Pseudomonas aeruginosa in Blood from Patients with Severe Thermal Injuries. PLoS One 2016, 11, No. e0149229.

(28) Tielen, P.; Rosin, N.; Meyer, A.-K.; Dohnt, K.; Haddad, I.; Jänsch, L.; Klein, J.; Narten, M.; Pommerenke, C.; Scheer, M.; Schobert, M.; Schomburg, D.; Thielen, B.; Jahn, D. Regulatory and Metabolic Networks for the Adaptation of Pseudomonas aeruginosa Biofilms to Urinary Tract-Like Conditions. PLoS One 2013, 8, No. e71845.

(29) Wang, J.; Mushegian, A.; Lory, S.; Jin, S. Large-Scale Isolation of Candidate Virulence Genes of Pseudomonas aeruginosa by in Vivo Selection. Proc. Natl. Acad. Sci. U. S. A. 1996, 93, 10434-10439.

(30) Britigan, B. E.; Roeder, T. L.; Rasmussen, G. T.; Shasby, D. M.; McCormick, M. L.; Cox, C. D. Interaction of the Pseudomonas aeruginosa Secretory Products Pyocyanin and Pyochelin Generates Hydroxyl Radical and Causes Synergistic Damage to Endothelial Cells. Implications for Pseudomonas-Associated Tissue Injury. J. Clin. Invest. 1992, 90, 2187-2196.

(31) Coffman, T. J.; Cox, C. D.; Edeker, B. L.; Britigan, B. E. Possible Role of Bacterial Siderophores in Inflammation. Iron Bound to the Pseudomonas Siderophore Pyochelin Can Function as a Hydroxyl Radical Catalyst. J. Clin. Invest. 1990, 86, 1030-1037.

(32) Cox, C. D. Iron Uptake with Ferripyochelin and Ferric Citrate by Pseudomonas aeruginosa. J. Bacteriol. 1980, 142, 581-587.

(33) Hoegy, F.; Mislin, G. L. A.; Schalk, I. J. Pyoverdine and Pyochelin Measurements. Methods Mol. Biol. 2014, 1149, 293-301.

(34) Reimmann, C.; Patel, H. M.; Serino, L.; Barone, M.; Walsh, C. T.; Haas, D. Essential PchG-Dependent Reduction in Pyochelin Biosynthesis of Pseudomonas aeruginosa. J. Bacteriol. 2001, 183, 813820.

(35) Sambrook, J.; Fritsch, E. F.; Maniatis, T. Molecular Cloning: A Laboratory Manual; Cold Spring Harbor Laboratory Press, 1989, No. Ed. 2.

(36) Visca, P.; Ciervo, A.; Sanfilippo, V.; Orsi, N. Iron-Regulated Salicylate Synthesis by Pseudomonas Spp. Microbiology 1993, 139, 1995-2001.

(37) Visca, P.; Serino, L.; Orsi, N. Isolation and Characterization of Pseudomonas aeruginosa Mutants Blocked in the Synthesis of Pyoverdin. J. Bacteriol. 1992, 174, 5727-5731.

(38) Bonchi, C.; Frangipani, E.; Imperi, F.; Visca, P. Pyoverdine and Proteases Affect the Response of Pseudomonas aeruginosa to Gallium in Human Serum. Antimicrob. Agents Chemother. 2015, 59, 56415646.

(39) Porcaro, F.; Bonchi, C.; Ugolini, A.; Frangipani, E.; Polzonetti, G.; Visca, P.; Meneghini, C.; Battocchio, C. Understanding the Biomimetic Properties of Gallium in Pseudomonas aeruginosa: An XAS and XPS Study. Dalton Trans. 2017, 46, 7082-7091.

(40) Visca, P.; Colotti, G.; Serino, L.; Verzili, D.; Orsi, N.; Chiancone, E. Metal Regulation of Siderophore Synthesis in Pseudomonas aeruginosa and Functional Effects of SiderophoreMetal Complexes. Appl. Environ. Microbiol. 1992, 58, 2886-2893.

(41) Zhang, S.; Chen, Y.; Potvin, E.; Sanschagrin, F.; Levesque, R. C.; McCormack, F. X.; Lau, G. W. Comparative Signature-Tagged
Mutagenesis Identifies Pseudomonas Factors Conferring Resistance to the Pulmonary Collectin SP-A. PLoS Pathog. 2005, 1, No. e31.

(42) Cox, C. D.; Graham, R. Isolation of an Iron-Binding Compound from Pseudomonas aeruginosa. J. Bacteriol. 1979, 137, 357-364.

(43) Patel, H. M.; Tao, J.; Walsh, C. T. Epimerization of an LCysteinyl to a d-Cysteinyl Residue during Thiazoline Ring Formation in Siderophore Chain Elongation by Pyochelin Synthetase from Pseudomonas aeruginosa. Biochemistry 2003, 42, 10514-10527.

(44) Venkateswara Rao, B.; Dhokale, S.; Rajamohanan, P. R.; Hotha, S. A Tetrazine Templated Method for the Synthesis of Ternary Conjugates. Chem. Commun. 2013, 49, 10808-10810.

(45) Zamri, A.; Abdallah, M. A. An Improved Stereocontrolled Synthesis of Pyochelin, Siderophore of Pseudomonas aeruginosa and Burkholderia cepacia. Tetrahedron 2000, 56, 249-256.

(46) Milton, D. L.; O’Toole, R.; Horstedt, P.; Wolf-Watz, H. Flagellin A Is Essential for the Virulence of Vibrio anguillarum. J. Bacteriol. 1996, 178, 1310-1319.

(47) Voisard, C.; Bull, C.; Keel, C.; Laville, J.; Maurhofer, M.; Schnider, U.; Défago, G.; Haas, D.; In O’Gara, F.; Dowling, D. N.; Boesten, B. (Eds) Molecular Ecology of Rhizosphere Microorganisms; AGRIS, 1994, 67-89.

(48) Hoang, T. T.; Kutchma, A. J.; Becher, A.; Schweizer, H. P. Integration-Proficient Plasmids for Pseudomonas aeruginosa: SiteSpecific Integration and Use for Engineering of Reporter and Expression Strains. Plasmid 2000, 43, 59-72.

(49) Liang, G.; Zhao, Z.; Wei, Y.; Liu, K.; Hou, W.; Duan, Y. Plasma Enhanced Label-Free Immunoassay for Alpha-Fetoprotein Based on a U-Bend Fiber-Optic LSPR Biosensor. RSC Adv. 2015, 5, 2399023998

(50) Webster, T. A.; Sismaet, H. J.; Conte, J. L.; Chan, I. J.; Goluch, E. D. Electrochemical Detection of Pseudomonas aeruginosa in Human Fluid Samples via Pyocyanin. Biosens. Bioelectron. 2014, 60, 265-270.

(51) Craney, A.; Hohenauer, T.; Xu, Y.; Navani, N. K.; Li, Y.; Nodwell, J. A Synthetic luxCDABE Gene Cluster Optimized for Expression in High-GC Bacteria. Nucleic Acids Res. 2007, 35, No. e46.

(52) Welsh, D. K.; Noguchi, T. Cellular Bioluminescence Imaging. Cold Spring Harbor Protoc. 2012, 2012, pdb.top070607.

(53) Becher, A.; Schweizer, H. P. Integration-Proficient Pseudomonas aeruginosa Vectors for Isolation of Single-Copy Chromosomal LacZ and Lux Gene Fusions. BioTechniques 2000, 29, 948-952.

(54) Stevenson, K.; McVey, A. F.; Clark, I. B. N.; Swain, P. S.; Pilizota, T. General Calibration of Microbial Growth in Microplate Readers. Sci. Rep. 2016, 6, 38828.

(55) Cunrath, O.; Graulier, G.; Carballido-Lopez, A.; Pérard, J.; Forster, A.; Geoffroy, V. A.; Saint, A. P.; Bumann, D.; Mislin, G. L. A.; Michaud-Soret, I.; Schalk, I. J.; Fechter, P. The Pathogen Pseudomonas aeruginosa Optimizes the Production of the Siderophore Pyochelin Upon Environmental Challenges. Metallomics 2020, 12, 2108-2120.

(56) Youard, Z. A.; Mislin, G. L. A.; Majcherczyk, P. A.; Schalk, I. J.; Reimmann, C. Pseudomonas Fluorescens CHA0 Produces EnantioPyochelin, the Optical Antipode of the Pseudomonas aeruginosa Siderophore Pyochelin. J. Biol. Chem. 2007, 282, 35546-35553.

(57) Braud, A.; Hannauer, M.; Mislin, G. L. A.; Schalk, I. J. The Pseudomonas aeruginosa Pyochelin-Iron Uptake Pathway and Its Metal Specificity. J. Bacteriol. 2009, 191, 3517-3525.

(58) Lin, P.-C.; Youard, Z. A.; Reimmann, C. In Vitro-Binding of the Natural Siderophore Enantiomers Pyochelin and Enantiopyochelin to Their AraC-Type Regulators PchR in Pseudomonas. BioMetals 2013, 26, 1067-1073

(59) Cunrath, O.; Geoffroy, V. A.; Schalk, I. J. Metallome of Pseudomonas aeruginosa: A Role for Siderophores. Environ. Microbiol. 2016, 18, 3258-3267.

(60) Medeiros, A. A.; O’Brien, T. F.; Wacker, W. E. C.; Yulug, N. F. Effect of Salt Concentration on the Apparent In-Vitro Susceptibility of Pseudomonas and Other Gram-Negative Bacilli to Gentamicin. J. Infect. Dis. 1971, 124, S59-S64.

(61) Cheng, K.; Smyth, R. L.; Govan, J. R.; Doherty, C.; Winstanley, C.; Denning, N.; Heaf, D. P.; van Saene, H.; Hart, C. A. Spread of $\beta$ - 
Lactam-Resistant Pseudomonas aeruginosa in a Cystic Fibrosis Clinic. Lancet. 1996, 348, 639-642.

(62) Frangipani, E.; Bonchi, C.; Minandri, F.; Imperi, F.; Visca, P. Pyochelin Potentiates the Inhibitory Activity of Gallium on Pseudomonas aeruginosa. Antimicrob. Agents Chemother. 2014, 58, $5572-5575$.

(63) Hoegy, F.; Lee, X.; Noel, S.; Rognan, D.; Mislin, G. L. A.; Reimmann, C.; Schalk, I. J. Stereospecificity of the Siderophore Pyochelin Outer Membrane Transporters in Fluorescent Pseudomonads. J. Biol. Chem. 2009, 284, 14949-14957.

(64) Fila, G.; Krychowiak, M.; Rychlowski, M.; Bielawski, K. P.; Grinholc, M. Antimicrobial Blue Light Photoinactivation of Pseudomonas aeruginosa: Quorum Sensing Signaling Molecules, Biofilm Formation and Pathogenicity. J. Biophotonics 2018, 11, No. e201800079.

(65) Szittner, R.; Meighen, E. Nucleotide Sequence, Expression, and Properties of Luciferase Coded by lux Genes from a Terrestrial Bacterium. J. Biol. Chem. 1990, 265, 16581-16587.

(66) Meyer, J. M.; Neely, A.; Stintzi, A.; Georges, C.; Holder, I. A. Pyoverdin Is Essential for Virulence of Pseudomonas aeruginosa. Infect. Immun. 1996, 64, 518-523.

(67) Takase, H.; Nitanai, H.; Hoshino, K.; Otani, T. Impact of Siderophore Production on Pseudomonas aeruginosa Infections in Immunosuppressed Mice. Infect. Immun. 2000, 68, 1834-1839. 